\title{
Anti-proliferative activity of a novel tricyclic triterpenoid acid from Commiphora africana resin against four human cancer cell lines
}

\author{
Worku Dinku', Johan Isaksson², Fredrik Garnås Rylandsholm² ${ }^{2}$, Petr Bouřr3 , Eva Brichtová ${ }^{3,4}$, Sang Un Choi ${ }^{5}$, \\ Sang-Ho Lee ${ }^{5}$, Young-Sik Jung ${ }^{5}$, Zae Sung No ${ }^{6}$, John Sigurd Mjøen Svendsen², Arne Jørgen Aasen ${ }^{2}$ \\ and Aman Dekebo ${ }^{*}$
}

\begin{abstract}
Myrrh, a resin derived from the damaged bark of Commiphora genus, has traditionally been used for treatment of various human diseases, such as amenorrhea, ache, tumors, fever, and stomach pains. In spite of this widespread use of the myrrh in Ethiopia, the pharmacological activity and chemical composition have not been studied in detail. A new tricyclic triterpene acid (3S,4S,14S,7E, 17E,21Z)-3,30-dihydroxypodioda-7,17,21-trien-4-carboxylic acid (commafric A) has been isolated from a crude methanolic extract of Commiphora africana (A. Rich.) Engl. resin along with the known pentacyclic triterpene a-amyrin. The structure of commafric A was characterized using different spectroscopic techniques such as $1 \mathrm{D}$ and $2 \mathrm{D}$ NMR, IR, and VCD combined with computations. The anti-proliferative activity of both isolated compounds was evaluated using SRB based colorimetric cellular assay against four human cancer cell lines. Etoposide was used as a positive control. Commafric A showed significant anti-proliferative effects against non-small cell lung cancer (A549) with $I_{50}$ values of $4.52 \mu \mathrm{g} / \mathrm{ml}$. The pentacyclic triterpene a-amyrin showed a weak antiproliferative activity against A2780 (ovarian cancer), MIA-PaCa-2 (pancreatic cancer), and SNU638 (stomach cancer) cell lines tested with $I C_{50}$ values ranging 9.28 to $28.22 \mu \mathrm{g} / \mathrm{ml}$. Commafric A possessed anti-proliferative activity against non-small cell lung cancer (A549), which suggests that commafric A has potential to be further optimized being a lead compound in the search for new drugs against cancer diseases.
\end{abstract}

Keywords: Commiphora africana, Commafric A, Anti-proliferative, SRB, A549 cell line

\section{Introduction}

Natural products are very inspiring in the drug discovery process. Aziz et al. [1] reviewed several drugs that have been obtained from different plant sources. Some of them can be obtained from Commiphora africana (A. Rich.) Engl. (Burseraceae), which is a bush about $1.5 \mathrm{~m}$ tall and is wide-spread in African countries, such as Sudan, Ethiopia, Eritrea, Somalia, Kenya, Uganda, and Mozambique [2]. Roots, bark and leaves are traditionally used to treat

\footnotetext{
*Correspondence: amandekeb@gmail.com

1 Department of Applied Chemistry, Adama Science and Technology University, Adama, Ethiopia

Full list of author information is available at the end of the article
}

measles, hyperlipidemia, and cardiovascular disorders [3, 4]. The leaves are also used as a sedative and soporific [3], and the resin is used for antiseptic washes and baths to treat skin infections, sores, and leprosy [5]. Ethnobotanical information has indicated that bark, resin, and leaves of C. africana are used to treat snakebite, skin wounds, tumor, stomachache, and as anti-ticks [6]. A fraction obtained after partitioning the crude ethanolic extract roots of $C$. africana exhibited a promising in vitro antimicrobial activity [4].

The resin of C. africana contains betulin [7], which has been shown to have antitumor activity, especially in combination with cholesterol [8]. Betulinic acid derivatives can inhibit HIV-1 [9]. Other Commiphora species 
have also provided pharmaceutically interesting compounds. Furanoeudesma-1,3-diene, the major compound of myrrh [10,11], has been reported to exhibit analgesic activity in mice [12].

Previously, we have described oxygenated furanosesquiterpenes, curzerenone, and furanodienone from the resins of C. sphaerocarpa (Chiov.), C. holtziana (Engl.), and $C$. kataf [11, 13, 14]. Messina et al. [15] has shown that furanodienone has anti-inflammatory, antimicrobial, and anticancer activities. Additionally, the cytotoxicity of nordammarane triterpenes, such as vibusambucin A, $\quad 12 \beta$-hydroxy-3,15-dioxo-20,21,22-23,24,25,26,27octanordammarane, and hupehenol $\mathrm{A}$ against $\mathrm{KB}$, HepG-2, LU-1, and MCF-7 cell lines has been reported [16]. The resins of $C$. confusa contain triterpenes of the dammarane type [17] with moderate cytotoxic activity against HepG2 [18]. From the resin of C. erlangeriana we have previously isolated polygamain-type lignans named erlangerin $\mathrm{A}$, and erlangerin $\mathrm{B}$, and two lignans related to podophyllotoxin, erlangerin $C$, and erlangerin $D$ [19]. The effects of the erlangerins $C$ and $D$ are closely related to those of podophyllotoxin. They induce concentrationdependent cytotoxicity in the murine macrophage cells (RAW 264.7) and a cytostatic effect in HeLa, EAhy926, and L929 cell lines [20].

In spite of the use of Commiphora africana in traditional medicine, to the best of our knowledge, there has been no study aimed at isolation and characterization of anti-proliferative constituents of this plant. As part of the exploration of the pharmacological potential of the resins from Commiphora genus, we herein report the isolation, structural elucidation, and anti-proliferative activity screening of a new oxygenated podioda-7,17,21-triene $[21,22]$ and $\alpha$-amyrin obtained from C. africana.

\section{Materials and methods Plant material}

Resins and botanical specimens of C. africana were collected from district of Yabello, Borena zone, Ethiopia in December 2016 and identified by a botanist Shambel Alemu at the Biology Department, Addis Ababa University. A voucher specimen has been deposited at the National Herbarium (number: 072801) of Addis Ababa University, Addis Ababa, Ethiopia. This tree is known by its vernacular name HAMMESA DiHRO (Afaan Oromo). There is no permission required to collect samples from wild to investigate their chemical composition and evaluate their anti-proliferative effects.

\section{Extraction and isolation}

The resin $(322.5 \mathrm{~g})$ of $C$. africana was air dried and extracted with methanol $(1 \mathrm{~L} \times 3)$ for 3 days at $25{ }^{\circ} \mathrm{C}$. The solvent was removed in vacuo to yield a yellow extract (151.2 g, 46.82\%). The extract (80.0 g) was suspended in water $(800 \mathrm{ml})$ and successively partitioned with $n$-hexane $(800 \mathrm{ml} \times 3)$, chloroform $(800 \mathrm{ml} \times 3)$, EtOAc $(800 \mathrm{ml} \times 3)$, and $n-\mathrm{BuOH}(800 \mathrm{ml} \times 3)$ yielding an $n$-hexane (33.39 g, 40.22\%), a chloroform (41.26 g, $49.7 \%)$, an EtOAc (0.11 g, 0.132\%), and an $n$-butanol fraction $(0.074 \mathrm{~g}, 0.093 \%)$. Part of the $n$-hexane fraction $(7 \mathrm{~g})$ was flash chromatographed on a silica gel column using $n$-hexane/EtOAc (7:3) as an eluent furnishing commafric A (1) (430 mg), and $\alpha$-amyrin (2) (22 mg) (Fig. 1).

\section{General experimental procedure}

Melting points are uncorrected. TLC was performed on precoated plates (Silica gel $60 \mathrm{~F}_{254}$, Merck) using $n$-hexane/EtOAc/MeOH (10:10:0.1) as a developing solvent and with vanillin- $\mathrm{H}_{2} \mathrm{SO}_{4}$ as the detecting reagent. CC was performed on silica gel. IR spectra were measured on a Perkin Elmer 1600 instrument using $\mathrm{KBr}$ tablets. Optical rotation was measured on a Perkin-Elmer 241 polarimeter. UV spectra were recorded on a Shimadzu UV-VIS spectrophotometer. LC-Mass was acquired on Waters ACQUITY H-CLASS Liquid Chromatograph/ SQD2 Mass Spectrometer; Injection mode: FIA, Eluent: Methanol/Water $(10 \mathrm{mM}$ ammonium acetate $)=70 / 30$ flow rate: $0.3 \mathrm{ml} / \mathrm{min}$, Ionization mode: ESI (positive), Capillary voltage: $3 \mathrm{kV}$, Cone voltage: $30 \mathrm{~V}$. HRESIMS data were obtained on Waters ACQUITY UPLC I - Class Liquid Chromatograph/TQ-S micro Tandem Mass-Spectrometer, Ionization mode: electrospray ionization (ESI), Mass Analyzer, JMS-700 Mass High Resolution Mass Spectrometer (Jeol LTD, Tokyo, Japan): Tandem (triple) quadrupole at mass range of $5-2000 \mathrm{~m} / \mathrm{z}$ and scan speed $15,000 \mathrm{Da} / \mathrm{sec}$.

\section{Nuclear magnetic resonance spectroscopy}

${ }^{1} \mathrm{H}$ and ${ }^{13} \mathrm{C}$ NMR data for commafric A (1) was acquired on an Avance III HD spectrometer (BrukerBioSpin $\mathrm{GmbH}$, Germany) equipped with an inverse detected TCI cryoprobe with a cryogenic enhancement for ${ }^{1} \mathrm{H},{ }^{2} \mathrm{H}$, and ${ }^{13} \mathrm{C}$, operating at $600 \mathrm{MHz}$ for ${ }^{1} \mathrm{H}$. All spectra were recorded using TopSpin $3.5 \mathrm{pl} 7$ at $298 \mathrm{~K}$ in dichloromethane- $d_{2}$ and chloroform- $d_{1}$, using gradient selected and adiabatic inversion versions of pulse sequences where applicable. Analysis of $N O E$ buildup for compound $\mathbf{1}$ was performed by complete relaxation matrix analysis using Mspin 2.3.2694 (MestreLab Research S. L., Spain). The results are presented as Boltzmann averaged NOE enhancement across the conformational ensemble generated for analysis of IR and VCD section. The sample for anisotropic NMR measurements $(10 \mathrm{mg})$ was dissolved in $\mathrm{CDCl}_{3}$ with $0.03 \%$ TMS to which increasing amounts 


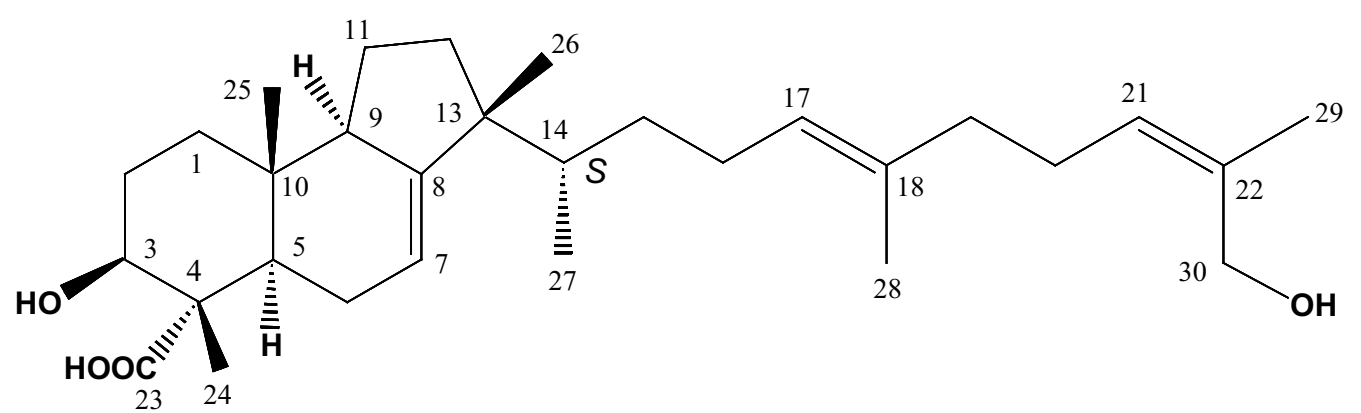

Commafric A (1)

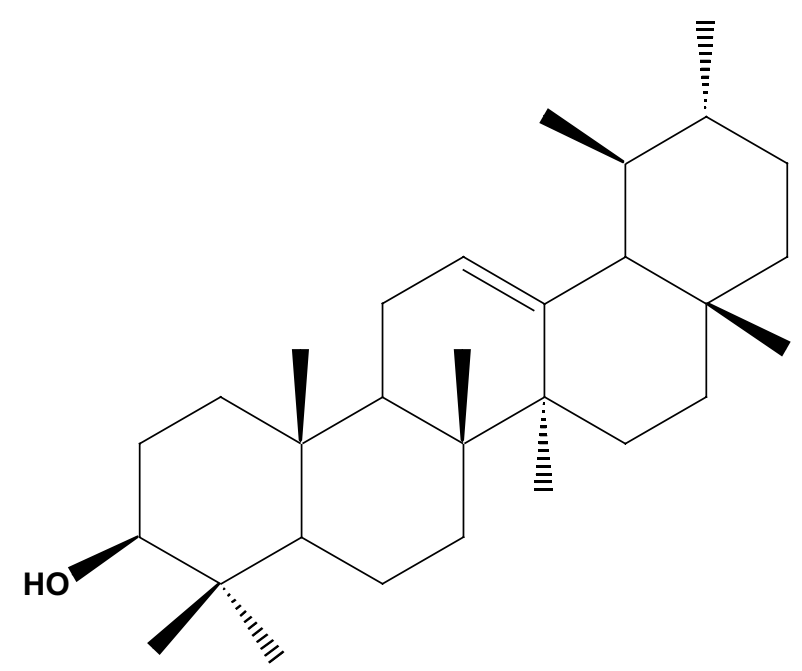

$\alpha$-amyrin (2)

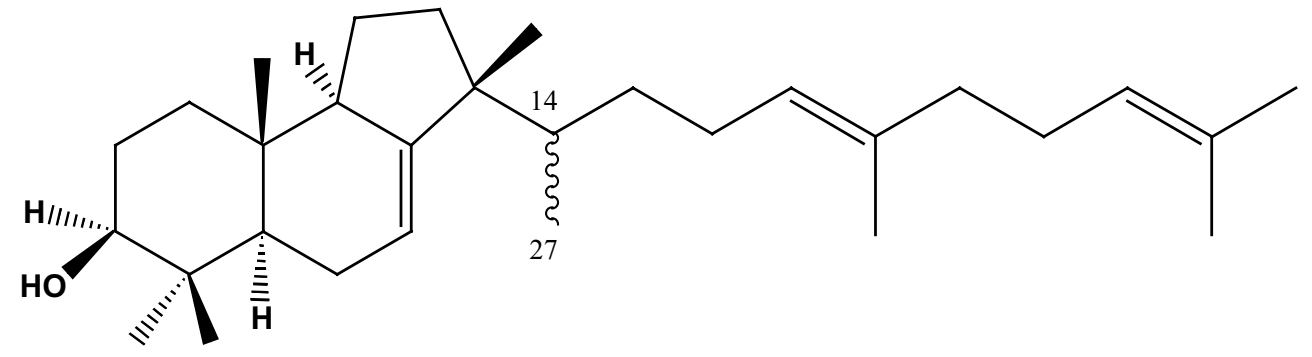

Podioda-7,17,21-trienol (3)

Fig. 1 Chemical structures of compounds isolated from C. africana and a reference compound podioda -7,17,21-trienol (3)

of poly- $\gamma$-benzyl-L-glutamate (PBLG, 150,000300,000 Da, Sigma-Aldrich CAS 25014-27-1) was added to yield weight-to-volume ratios of $7.9 \%, 12.1 \%$, and $16.2 \%$. For compound 1 1D carbon, CLIP-HSQC, IPAP-HSQC, and J-res carbon was acquired to extract the ${ }^{1} J_{\mathrm{CH}}$ coupling constants and anisotropic carbon shifts. The data treatment is thoroughly described in additional file.

Experimental vibrational circular dichroism (VCD) spectra VCD and absorption spectra of $\mathbf{1}$ were measured in $\mathrm{CDCl}_{3}$ solutions $(\sim 1 \mathrm{mg} / 100 \mu \mathrm{l})$ using a $\mathrm{BaF}_{2}$ cell of an optical path of $50 \mu \mathrm{m}$ and a BioTools ChiralIR-2X 
instrument. Spectra of pure $\mathrm{CDCl}_{3}$ solvent were subtracted as a baseline; the accumulation time was $\sim 12 \mathrm{~h}$ using blocks of 1200 scans and $4 \mathrm{~cm}^{-1}$ resolution.

\section{Computations}

Using the Gaussian suite of programs [23] a systematic conformer search of compound 1 was performed considering the three torsional angles in the vicinity of the tricyclic system. Other $\mathrm{C}-\mathrm{C}-\mathrm{C}-\mathrm{C}$ dihedral angles were all-trans and all-extended $\left(180^{\circ}\right)$ at the beginning of the optimizations and left to optimize without constraints. The B3LYP [24] PCM [25] (chloroform) $/ 6-31++G^{* * *}$ level was used for all quantum chemistry. For stable conformers thus obtained the magnetic field perturbation theory $[26,27]$ was used to simulate IR and VCD intensities; final spectra were obtained as a Boltzmann average, using a convolution with Lorentzian lines (FWHM $=10 \mathrm{~cm}^{-1}$ ). Since the consideration of the full molecular flexibility was not possible with our computational means, atomic axial tensors of the linear side chain (from carbon number 16) were deleted for VCD generation. The chain itself is not chiral and thus supposedly the error introduced by this approximation is small, whereas the dominant signal from the chiral more rigid molecular part may help to assign the absolute configuration. Alternated simulations of the spectra based on molecular dynamics were attempted as well, but did not provide results significantly different from the limited conformer model. Boltzmann-averaged isotropic shielding and spin-spin coupling constants were computed at the same level as for VCD.

\section{Tumor cell lines}

The cell lines used in this study were the human nonsmall cell lung cancer cell lines (A549), ovarian cancer cell line (A2780), pancreatic cancer cell line (MIA-Paca-2), and stomach cancer cell line (SNU-638), and they were maintained using RPMI1640 cell growth medium (Gibco, Carlsbad, CA), supplemented with $5 \%$ fetal bovine serum (FBS) (Gibco), and grown at $37^{\circ} \mathrm{C}$ in a humidified atmosphere containing $5 \% \mathrm{CO}_{2}$ [28]. All the cancer cells used were adapted for 6 months at least to the RPMI1640 medium at Korea Research Institute of Chemical Technology, then used in the anti-proliferative assays. Cells were exposed to the isolated compounds at concentrations ranging from 0.1 to $30 \mu \mathrm{g} / \mathrm{ml}$.

\section{Anti-proliferative assessment}

All experiments were conducted by the NCI's protocol [28]. Experimental cultures were placed in 96-well microtiter plates (Corning) containing $0.15 \mathrm{ml}$ of growth medium per well with a cell density of $5 \times 10^{3}$ (A549, A2780, and MIA-Paca-2) and $1 \times 10^{4}$ (SNU-638). The culture was incubated at $37{ }^{\circ} \mathrm{C}$ and humidified by $5 \% \mathrm{CO}_{2}$ for 1 day. Then, media were aspirated off and added the test material in triplicate which was dissolved in media at varying concentrations. In case of necessity, the test material was dissolved in small amount of dimethyl sufoxide (DMSO), but the final concentration of DMSO in the medium did not exceed $0.5 \%$. The culture was incubated for additional 3 days. After 3 days of continuous drug exposure, the medium was removed by flicking plates over a sink. The cells attached to the plastic substratum were fixed by gently layering with $0.1 \mathrm{ml}$ of cold $10 \%$ trichloroacetic acid (TCA). Incubation at $4{ }^{\circ} \mathrm{C}$ for $1 \mathrm{~h}$ was followed by wash with tap water five times to remove TCA solution. After being washed and dried at RT overnight, TCA fixed cells were stained with $0.1 \mathrm{ml}$ of $0.4 \%$ sulforhodamine B (SRB) in $1 \%$ acetic acid per well for $30 \mathrm{~min}$. At the end of the staining period, SRB supernatant was removed and the remaining cells were rinsed with $1 \%$ acetic acid five times. It was dried until no standing moisture was visible, and then the bound dye in cells was extracted with $0.1 \mathrm{ml}$ of $10 \mathrm{mM}$ unbuffered Tris base ( $\mathrm{pH} 10.5)$ per well by stirring on a gyratory shaker for 5-10 min, followed by measured the optical density at $520 \mathrm{~nm}$ by MR700 microplate reader (Dynatech Laboratories). Antitumor activity of the test material at varying concentrations was estimated as the net growth \% of cells compared with that of control (without test material, net growth $=100 \%$ ). The dose-response curves of test material were constructed and the $\mathrm{IC}_{50}$ value was calculated as the concentration of the test material that caused $50 \%$ inhibition of cell growth against the cancer lines A549, A2780, MIA-PaCa-2, and SNU638. Etoposide, a standard drug was used as a positive control. $\mathrm{IC}_{50}$ values of etoposide were compared with those for crude extract, $n$-hexane fraction, and isolated compounds.

\section{Results}

\section{Isolation of compounds}

Flash column chromatography of the $n$-hexane fraction using $n$-hexane/EtOAc (7:3) as an eluent furnished two pure compounds: commafric A (1) the most abundant isolated molecule and the known compound $\alpha$-amyrin (2), were obtained as white solids. The structures of the isolated compounds were elucidated employing ${ }^{13} \mathrm{C}$ and ${ }^{1} \mathrm{H}$-NMR as well as 2D-NMR, IR, FT-ESI-MS mass fragmentation pattern, and comparing with literature data reported for structurally related compounds. The ${ }^{1} \mathrm{H}$ $\mathrm{NMR}$ and ${ }^{13} \mathrm{C}$ NMR data of compound 2 agreed with corresponding published data for $\alpha$-amyrin (2) [29-31].

\section{Characterization of compound 1}

Compound 1 was obtained as a white powder (mp 126-127 ${ }^{\circ} \mathrm{C}$ ), with $[\alpha]_{D}^{22}:+4^{\circ}\left(c\right.$ 1.0, $\left.\mathrm{CHCl}_{3}\right)$ and its 
molecular formula was established on the basis of a high resolution positive-ion mode HR-ESI-MS ${ }^{2}$ scanned from 170.00 to $600.00 \mathrm{~m} / \mathrm{z}$. The molecular formula was established as $\mathrm{C}_{30} \mathrm{H}_{48} \mathrm{O}_{4}$ on the basis of the positive-ion mode HRESIMS data due to $\mathrm{Na}$ adduct formation $(\mathrm{m} / \mathrm{z}$ 495.3442 [M+Na $]^{+}$, calcd. 495.3445) and NMR data indicating seven degrees of unsaturation (Additional file 1: Fig. S1). The two peaks with less intensity at $m / z 473.36$ and $m / z 455.3515$ corresponds to protonation of the molecule $[\mathrm{M}+\mathrm{H}]^{+}$and protonation of a dehydrate molecule respectively (Additional file 1: Fig. S1).

The UV spectrum of $\mathbf{1}$ (EtOH) exhibited an absorption band at $209 \mathrm{~nm}$ indicating the absence of conjugated double bonds. The experimental IR-spectrum agrees with the simulated spectrum of commafric A (Fig. 2); the most prominent features comprise free $\left(3607 \mathrm{~cm}^{-1}\right)$ and hydrogen-bonded $\left(3400 \mathrm{~cm}^{-1}\right) \mathrm{OH}$ stretching bands, split $\left(2956 / 2872 \mathrm{~cm}^{-1}\right) \mathrm{CH}$ stretching signal indicating the presence of both $\mathrm{sp}^{2}$ and $\mathrm{sp}^{3}$ carbons, and the $\mathrm{C}=\mathrm{O}$ stretching band $\left(1695 \mathrm{~cm}^{-1}\right)$.

${ }^{1} \mathrm{H}$ NMR resonances (Table 1 ) of $\mathbf{1}$ included two near triplets at $\delta_{\mathrm{H}} 5.30$ and 5.04, and one doublet of a triplet at $\delta_{\mathrm{H}} 5.16$, suggesting the presence of three olefinic protons. Two geminally coupled protons appearing as doublets at $\delta_{\mathrm{H}} 4.17$ and 4.07 indicated the presence one oxy methylene moiety. A signal integrated as one proton at $\delta_{\mathrm{H}} 4.02$ suggested the presence of an oxy methine group. Two moderately deshielded methyl signals were observed (1.57 and $1.77 \mathrm{ppm}$ ), indicating that two methyls are attached to $\mathrm{sp}^{2}$ hybridized carbons (see Additional file 1: Fig. S2). Additionally, the compound has four aliphatic methyl signals $(0.75,0.86,0.91$, and 1.18$)$.

The ${ }^{13} \mathrm{C}$ NMR (Table 1 and Additional file 1: Fig. S3) and multiplicity edited HSQC/DEPT confirmed the presence of thirty carbons, of which seven were quaternary,

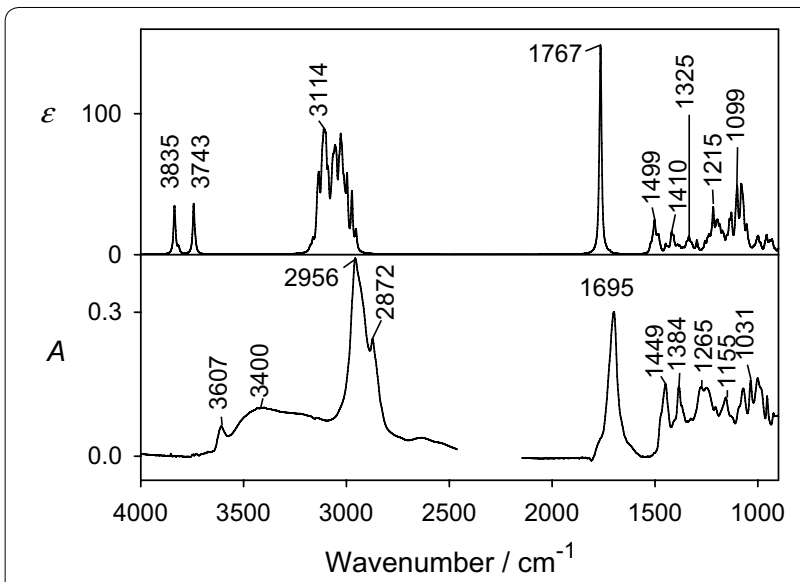

Fig. 2 Calculated (upper panel, raw DFT frequencies) and experimental (lower panel) IR spectra of commafric A ten methylene, seven methine, and six methyl groups. A set of 2D NMR experiments, HSQC, HMBC, H2BC, HSQC-TOCSY, DQF-COSY, and 1,1-ADEQUATE (Additional file 1: Fig. S4-S9), was used to establish the molecular framework of commafric A as a tricyclic triterpenoid with structural similarity to podioda-7,17,21trienol [21]. All carbon-carbon connections were unambiguously confirmed by 1,1-ADEQUEATE, except for the two quaternary to quaternary carbon bonds (C4 to $\mathrm{C} 23$ and $\mathrm{C} 8$ to $\mathrm{C} 13$ ), which did not correlate in this pulse sequence because of the absence of protons on both sides of the $\mathrm{C}-\mathrm{C}$ bond (Fig. $3 \mathrm{~b}$ ). The $\mathrm{C} 23$ carboxyl group could be placed by HMBC correlations to H3, H5, and $\mathrm{H} 24$ from $\mathrm{C} 23$, while the $\mathrm{C} 8$ to $\mathrm{C} 13$ bond was confirmed by HMBC correlations between $\mathrm{H} 26$ and $\mathrm{H} 12$, and $\mathrm{C} 8$. The location of the hydroxymethylene group as well as the position of the 21, 22 double bond was confirmed by $2 \mathrm{D}$ HMBC (Fig. 3a), which showed three bond couplings between the olefinic proton $\mathrm{H} 21\left(\delta_{\mathrm{H}} 5.30\right)$ and the carbons at the $\mathrm{C} 29$ methyl group $(\delta 21.4)$ and the C30 hydroxymethylene carbon $\left(\delta_{\mathrm{C}} 61.5\right)$. Furthermore, H2BC two-bond couplings appeared between $\mathrm{C} 22$ and Me29 and hydroxymethylene protons $\mathrm{H} 30^{\prime \prime \prime \prime}$ (Fig. 3a).

\section{Determination of the relative configuration}

Based on ${ }^{3} J_{\mathrm{CH}}$ couplings measured by selective CLIPHSQMBC [32], as well as NOESY/ROESY analysis, the $\mathrm{C} 17 / \mathrm{C} 18$ configuration was determined as $E$ $\left({ }^{3} J_{\mathrm{C} 28 \mathrm{H} 17}=8.0 \mathrm{~Hz}\right.$ and $\left.{ }^{3} J_{\mathrm{C} 19 \mathrm{H} 17}=6.0 \mathrm{~Hz}\right)$ and the $\mathrm{C} 21 / \mathrm{C} 22$ configuration was determined as $Z\left({ }^{3} J_{\mathrm{C} 29 \mathrm{H} 21}=6.0 \mathrm{~Hz}\right.$ and ${ }^{3} J_{\mathrm{C} 30 \mathrm{H} 21}=9.3 \mathrm{~Hz}$, Additional file 1: Figs. S10-S12). These conclusions are based on the fact that the $\operatorname{trans}^{3}{ }^{3} J_{\mathrm{CH}}$ is expected to be stronger than the corresponding $c i s-{ }^{3} J_{\mathrm{CH}}$. This was also consistent with the direct observations of the presence of the $N O E_{\mathrm{H} 21 \mathrm{H} 29}$ and $R O E_{\mathrm{H} 21 \mathrm{H} 29}$ correlations, and the absence of the $N O E_{\mathrm{H} 21 \mathrm{H} 29}$ and $R O E_{\mathrm{H} 21 \mathrm{H} 29}$ correlations. The $Z$-configuration of the $\mathrm{C} 21$ to $\mathrm{C} 22$-double bond is also consistent with the ${ }^{13} \mathrm{C}$ NMR chemical shifts of C21, C22, C29, and C30 in previously reported compounds with similar side chain configurations [33, 34].

The relative configuration of the tricyclic system was established by NOESY and ROESY correlations (Additional file 1: Fig. S12) supplemented with some ${ }^{3} J_{\mathrm{HH}}$ and ${ }^{3} J_{\mathrm{CH}}$ couplings. Most notably, an N/ROE correlation trace between $\mathrm{H} 3-\mathrm{H} 5-\mathrm{H} 9-\mathrm{H} 11^{\prime \prime}-\mathrm{H} 12^{\prime \prime}$ place these protons below the ring plane while the trace between $\mathrm{H} 24-\mathrm{H} 25-$ $\mathrm{H} 11^{\prime}-\mathrm{H} 12^{\prime}-\mathrm{H} 26$ place these above the ring plane. The key correlations are displayed in Fig. 3c. The configuration at the $\mathrm{C} 14$ stereocenter could not be unambiguously determined from the N/ROE correlations without a full conformational analysis because of relatively free rotation about the $\mathrm{C} 13-\mathrm{C} 14$ bond. 
Table 1 NMR parameters of commafric $A$ in $\mathrm{CD}_{2} \mathrm{Cl}_{2}:{ }^{1} \mathrm{H}(600 \mathrm{MHz})$ and ${ }^{13} \mathrm{C}(150 \mathrm{MHz}) \mathrm{NMR}, \mathrm{HMBC}, \mathrm{H} 2 \mathrm{BC}$, ADEQUATE-1,1, and ROESY

\begin{tabular}{|c|c|c|c|c|c|c|}
\hline No. & $\delta_{\mathrm{c}}$ & $\delta_{\mathrm{H}}($ multi, $\mathrm{J}$ in $\mathrm{Hz}$ ) & $\mathrm{HMBC}(\mathrm{H} \rightarrow \mathrm{C})^{\mathrm{d}}$ & $\begin{array}{l}\text { H2BC } \\
(H \rightarrow[H] C)^{d}\end{array}$ & $\begin{array}{l}\text { 1,1-ADEQUATE } \\
([\mathrm{H}] \mathrm{C} \rightarrow \mathrm{C})^{\mathrm{d}}\end{array}$ & Key ROESY \\
\hline 1 & 38.1 & $1.72(\mathrm{dt}, J=13.3,3.1) / 1.32\left(\mathrm{~m}^{\mathrm{c}}\right)$ & 25 & $2^{\prime \prime \prime \prime}$ & $2^{\prime \prime \prime \prime}$ & $2^{\prime \prime \prime \prime}, 25,2^{\prime \prime \prime \prime}$ \\
\hline 2 & 27.3 & $1.67\left(\mathrm{~m}^{\mathrm{c}}\right)$ & 3 & $1^{\prime}, 1^{\prime \prime}, 3$ & $1^{\prime}, 1^{\prime \prime}, 3$ & $1^{\prime \prime \prime \prime}, 25$ \\
\hline 3 & 76.2 & $4.02(\mathrm{dd}, J=11.2,4.7)$ & $1^{\prime \prime}, 2^{\prime \prime}, 5,24$ & $2^{\prime \prime \prime \prime}$ & $2^{\prime \prime \prime \prime}$ & $2^{\prime \prime \prime \prime}, 5$ \\
\hline 4 & 52.9 & & $2^{\prime}, 2^{\prime \prime}, 3,5,24$ & & $3,5,24$ & \\
\hline 5 & 46.6 & $1.88\left(\mathrm{~m}^{\top}\right)$ & 24,25 & $6^{\prime}, 6^{\prime \prime}$ & $6^{\prime}, 6^{\prime \prime}$ & 3,9 \\
\hline 6 & 25.8 & $2.05\left(\mathrm{~m}^{\mathrm{c}}\right) / 1.80\left(\mathrm{~m}^{\mathrm{c}}\right)$ & & 5,7 & 5,7 & $7,24,25$ \\
\hline 7 & 114.0 & $5.16(\mathrm{dt}, J=5.1,2.6)$ & $6^{\prime}$ & $6^{\prime}, 6^{\prime \prime}$ & $6^{\prime}, 6^{\prime \prime}$ & 14 \\
\hline 8 & 151.0 & & $6^{\prime \prime \prime \prime}, 11^{\prime \prime \prime \prime}, 12^{\prime \prime \prime \prime}, 26$ & & 7,9 & \\
\hline 9 & 59.5 & $2.01\left(\mathrm{~m}^{\mathrm{c}}\right)$ & $1^{\prime}, 5,11^{\prime}, 12^{\prime \prime \prime \prime}, 25$ & $11^{\prime}, 11^{\prime \prime}$ & $11^{\prime}, 11^{\prime \prime}$ & $1^{\prime \prime}, 5,11^{\prime \prime}, 12^{\prime \prime}$ \\
\hline 10 & 34.1 & & $1^{\prime \prime \prime \prime}, 5,25$ & & $1^{\prime}, 1^{\prime \prime}, 5,9,25$ & \\
\hline 11 & 23.1 & $1.25\left(\mathrm{~m}^{\mathrm{c}}\right) / 1.53\left(\mathrm{~m}^{\mathrm{c}}\right)$ & $12^{\prime \prime \prime \prime}$ & $12^{\prime \prime}$ & $9,12^{\prime}, 12^{\prime \prime}$ & $25,26 / 9$ \\
\hline 12 & 33.0 & $1.25\left(\mathrm{~m}^{\mathrm{c}}\right) / 1.48\left(\mathrm{~m}^{\mathrm{c}}\right)$ & $11^{\prime \prime \prime \prime}, 14,26^{a}$ & $11^{\prime}, 11^{\prime \prime}$ & $11^{\prime}, 11^{\prime \prime}$ & $26 / 9,15^{\prime} / \prime \prime, 27$ \\
\hline 13 & 48.3 & & $12^{\prime \prime}, 14,26,27$ & & $12^{\prime}, 12^{\prime \prime}, 14,26$ & \\
\hline 14 & 41.2 & $1.36\left(\mathrm{~m}^{\mathrm{c}}\right)$ & $9,12^{\prime \prime}, 26,27$ & $15^{\prime}, 27$ & $15^{\prime}, 27$ & $6^{\prime}, 6^{\prime \prime}, 7$ \\
\hline 15 & 33.0 & $1.34\left(\mathrm{~m}^{\mathrm{c}}\right) / 1.00\left(\mathrm{~m}^{\mathrm{C}}\right)$ & $16^{\prime \prime}, 27^{a}$ & $14,16^{\prime}, 16^{\prime \prime}$ & $14,16^{\prime}, 16^{\prime \prime}$ & \\
\hline 16 & 26.6 & $2.02\left(\mathrm{~m}^{\mathrm{c}}\right) / 1.87\left(\mathrm{~m}^{\mathrm{c}}\right)$ & $15^{1 / 11}, 17^{b}$ & $15^{\prime \prime}, 17$ & $15^{\prime}, 15^{\prime \prime}, 17$ & \\
\hline 17 & 125 & $5.04(\mathrm{ddq}, J=7.5,6.3,1.3)$ & $15^{\prime \prime \prime \prime}, 16^{\prime \prime \prime \prime}, 19^{\prime \prime \prime \prime}, 28$ & $16^{\prime}, 16^{\prime \prime}, 28^{*}$ & $16^{\prime}, 16^{\prime \prime}$ & \\
\hline 18 & 135 & & $16^{\prime \prime \prime \prime}, 19^{\prime \prime \prime \prime}, 28$ & & $17,19^{\prime}, 19^{\prime \prime}, 28$ & \\
\hline 19 & 40.0 & $1.96\left(\mathrm{~m}^{\mathrm{c}}\right) / 1.93\left(\mathrm{~m}^{\mathrm{c}}\right)$ & $20^{\prime \prime}, 28,29$ & $20^{\prime}, 20^{\prime \prime}$ & $20^{\prime}, 20^{\prime \prime}$ & \\
\hline 20 & 26.7 & $2.14\left(\mathrm{~m}^{\mathrm{c}}\right) / 2.09\left(\mathrm{~m}^{\mathrm{c}}\right)$ & $21^{b}$ & $19^{\prime}, 19^{\prime \prime}, 29^{* *}$ & $19^{\prime}, 19^{\prime \prime}, 21$ & \\
\hline 21 & 129.0 & $5.30(t, J=7.0)$ & $19^{\prime \prime \prime \prime}, 20^{\prime \prime \prime \prime}, 29,30^{\prime \prime \prime \prime}$ & $19^{\prime}, 19^{\prime \prime}, 29^{*}$ & $20^{\prime}, 20^{\prime \prime}$ & 29 \\
\hline 22 & 134.0 & & $20^{\prime \prime \prime \prime}, 29,30^{\prime \prime \prime \prime}$ & & $21,29,30^{\prime}, 30^{\prime \prime}$ & \\
\hline 23 & 181.0 & & $3,5,24$ & & & \\
\hline 24 & 10.7 & $1.18(s)$ & 3,5 & & & $6^{\prime}, 25$ \\
\hline 25 & 14.1 & $0.75(s)$ & $1^{\prime \prime}, 5$ & & & $1^{\prime}, 2^{\prime \prime \prime \prime}, 6^{\prime}, 11^{\prime}, 24$ \\
\hline 26 & 26.8 & $0.91(s)$ & $12^{1 / 116}$ & & & $11^{\prime}, 12^{\prime}$ \\
\hline 27 & 15.1 & $0.86(d, J=6.8)$ & $14,15^{\prime \prime \prime \prime}$ & 14 & 14 & $12^{\prime \prime}$ \\
\hline 28 & 16.4 & $1.57(\mathrm{~s})$ & $17,19^{1 / \prime \prime}$ & & & \\
\hline 29 & 21.4 & $1.77(\mathrm{~s})$ & $21,30^{1 / \prime \prime}$ & & & 21 \\
\hline 30 & 61.5 & $4.07(\mathrm{~d}, J=11.7) / 4.17(\mathrm{~d}, J=11.7)$ & 21,29 & & & \\
\hline
\end{tabular}

averlap between $\mathrm{C} 12$ and $\mathrm{C} 15$

b Overlap between C16, C20, and C26

c Overlapping multiplets in ${ }^{1} \mathrm{H}$

${ }^{d}$ Correlations listed on each receiving carbon row from the denoted proton(s)

\section{Determination of the C14 configuration} Vibrational circular dichroism spectroscopy

In order to relate the measured VCD spectra to the structure, theoretical VCD spectra were simulated computationally. The theoretical modelling focused on the tricyclic system supposedly dominating in VCD spectrum, because a full conformer analysis $\left(>10^{6}\right.$ possible conformers) was not possible with available computational means. A reduced ensemble of 27 conformers was generated by $120^{\circ}$ rotations around the $\mathrm{C} 13-\mathrm{C} 14, \mathrm{C} 4-$ $\mathrm{C} 23$, and $\mathrm{C} 3-\mathrm{O} 3$ bonds only, and relative conformer energies were obtained for both the $R$ and $S \mathrm{C} 14$ isomers. The molecular tail (C14-C30) was kept in the extended conformation and its contribution to VCD was not considered. The equilibrium geometries and spectral properties were calculated using the Gaussian software [24] and the B3LYP/6-311++G**/PCM $\left(\mathrm{CHCl}_{3}\right)$ level of theory, relative enthalpies were used for property averaging. The simulation reproduced some spectral features observed experimentally (Fig. 4), although the theoretical $R$ and $S$ VCD sign patterns of 1 are similar. The $1150-1000 \mathrm{~cm}^{-1}$ spectral region is however predicted to be significantly 


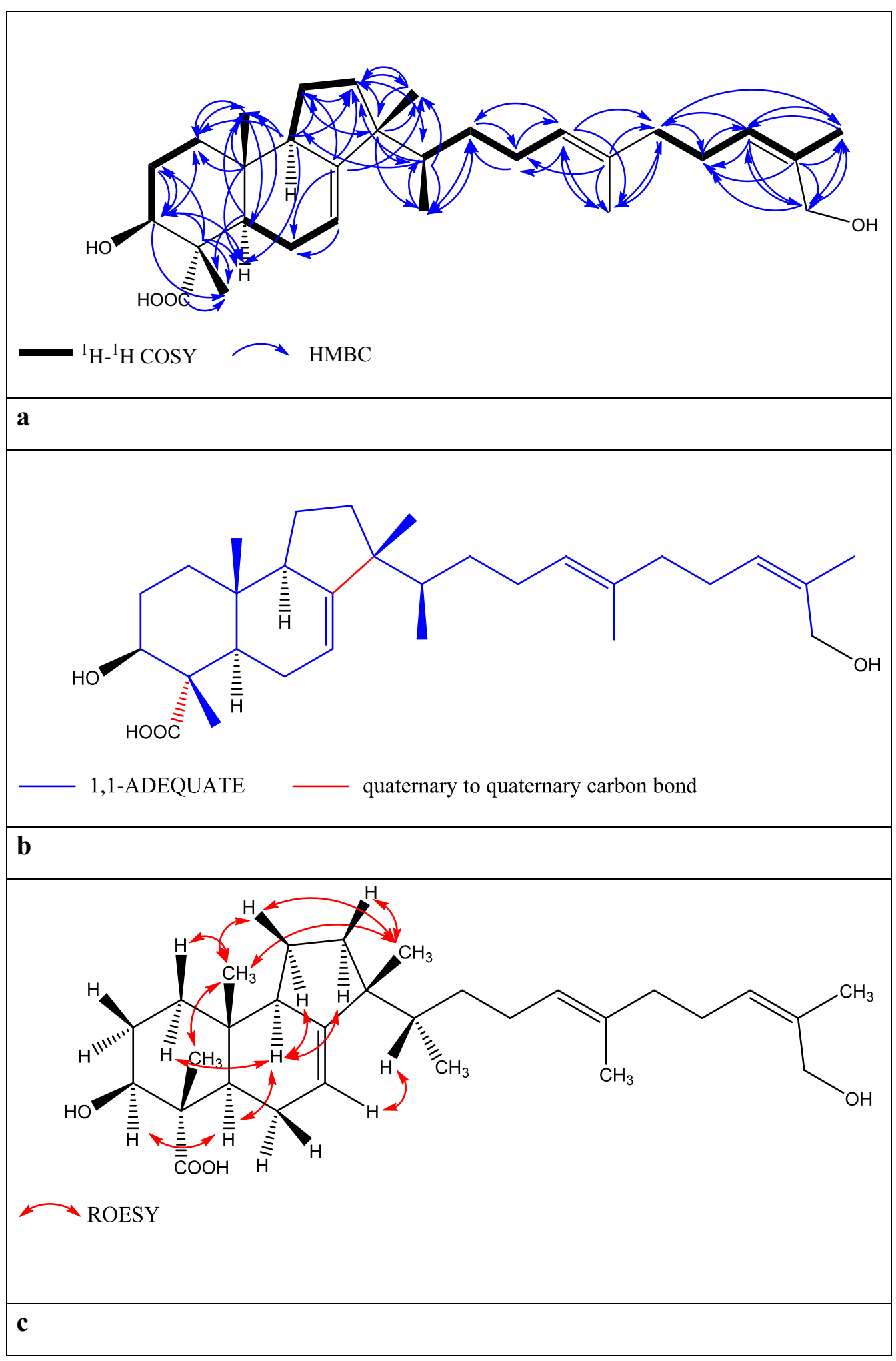

Fig. 3 2D NMR correlations through bonds, a COSY, HMBC and, b 1,1-ADEQUATE; and through space, c NOESY/ROESY of commafric A 


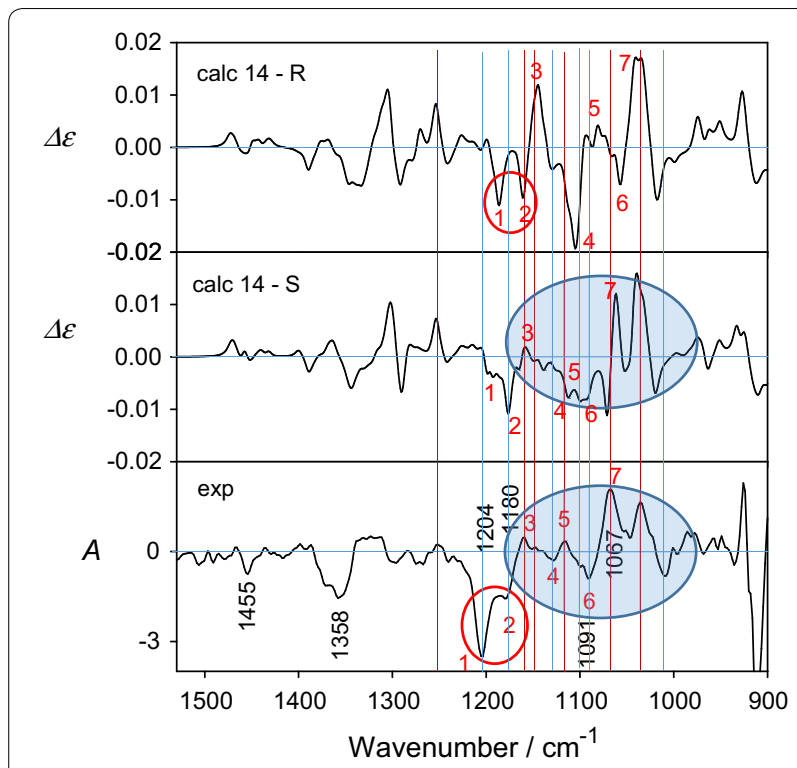

Fig. 4 VCD spectra calculated for the $R$ and S C14 isomers (upper and middle panels, frequency scaled by 0.967) and the experiment (lower panel). Experimental wavenumbers are denoted in black, and selected bands are assigned identifiers denoted in red. Positive experimental bands are traced with red lines and negative experimental bands are traced with blue lines

Table 2 Calculated C13-C14 angular distribution ( $p, \%)$, for the $\mathrm{C} 14$ enantiomers

\begin{tabular}{|c|c|c|c|c|}
\hline & \multicolumn{2}{|c|}{ R-C14 } & \multicolumn{2}{|c|}{ S-C14 } \\
\hline & $p$ & $\tau(\delta \varepsilon \gamma)^{\alpha}$ & $p$ & $\overline{\tau(\delta \varepsilon \gamma)^{a}}$ \\
\hline Gauche + & 12 & 71.9 & 11.1 & 44.9 \\
\hline Gauche - & 87.7 & -58.9 & 11.7 & -64.9 \\
\hline Anti & 0.3 & -164.6 & 77.2 & 170.6 \\
\hline
\end{tabular}

a $\angle$ C26-C13-C14-C27, torsion angle between the two methyl groups as obtained for the optimized DFT geometries

different for the $R$ - and $S$ configurations, and comparison of the calculated and experimental VCD signs and relative intensities for this region strongly suggests the $S$ configuration on C14.

\section{Isotropic NMR parameters}

For a more detailed NMR data analysis of distances and coupling constants localized near the C14, only the three Boltzmann averaged rotamers around the C13-C14 bond were used. The H14 proton is preferentially pointing towards the edge of the ring system (and $\mathrm{H}-7$ ) in both the $R$ - and the $S$ C14 configurations (Table 2). This was problematic for using the otherwise very informative ${ }^{3} J_{\mathrm{CH}}$ couplings originating from the only proton (H14) directly attached to the rotating $\mathrm{C} 13-\mathrm{C} 14$ bond since
Table 3 Calculated and experimental ${ }^{3} \mathrm{~J}_{\mathrm{CH}}$ scalar couplings for the $\mathrm{C} 14$ enantiomers

\begin{tabular}{llllll}
\hline & Population & $\mathbf{3}_{\mathbf{C 8 H 1 4}}$ & $\mathbf{J}_{\mathbf{C 1 2 H 1 4}}$ & $\mathbf{J}_{\mathbf{C 2 6 H} \mathbf{4}}$ & Configuration \\
\hline Gauche + & 12 & 0.68 & 2.12 & 4.56 & $\mathrm{R}$ \\
Gauche - & 87.7 & 0.98 & 4.6 & 2.11 & \\
Anti & 0.3 & 4.79 & 0.82 & 3.29 & \\
Averaged & & 0.96 & 4.38 & 2.32 & \\
Gauche + & 11.1 & 5.2 & 3.16 & 0.87 & $\mathrm{~S}$ \\
Gauche - & 11.7 & 1.44 & 1.64 & 4.41 & \\
Anti & 77.2 & 0.68 & 4.4 & 2.55 & \\
Averaged & & 1.23 & 3.98 & 2.57 & \\
Experimental & & 0.8 & 5.3 & 3.7 & \\
\hline
\end{tabular}

a $\angle \mathrm{C} 26-\mathrm{C} 13-\mathrm{C} 14-\mathrm{C} 27$, torsion angle between the two methyl groups as obtained for the optimized DFT geometries

the dihedral angles formed between the H14-C14 vector and the $\mathrm{C} 13-\mathrm{C} 8, \mathrm{C} 12, \mathrm{C} 26$ vectors will be very similar for $R$ - and $S$. The predicted differences between the two configurations were smaller than $0.5 \mathrm{~Hz}$. The experimental couplings (Table 3) are in agreement with the calculated rotamer populations of both configurations. These couplings were very challenging to measure accurately experimentally as the signal of H14 overlaps with that of H15s. That made it necessary to use heavily chemical shift filtered selective methods and there is unavoidable phase modulation from J-coupling. Coupling sums were utilized because of significant second order/phase contributions. For all these reasons, the experimental error is estimated to at least $1 \mathrm{~Hz}$.

Furthermore, the possibility to determine the relative configuration from $N O E$ buildup rates involving the C27 methyl group were investigated. The C27 methyl group is predicted to be predominantly anti to the $\mathrm{C} 26$ methyl in the $S$-configuration and gauche to the $\mathrm{C} 26$ methyl in the $R$-configuration. NOE buildups are intrinsically difficult to quantify for flexible molecules due to the fact that they depend on the distance as $r^{-6}$. A scarcely populated rotamer can contribute significantly to the observed NOE if the two protons are positioned very close to each other. The measured NOEs around and across the C13-C14 bond (Additional file 1: Fig. S13) are not conclusive alone as both theoretical configurations result in $r^{2}$ values in the order of 0.7. However, the most important $N O E$ between $\mathrm{H} 26$ and $\mathrm{H} 27$ that is expected to be the most sensitive to the C14 configuration indicates the $S$-configuration. The weighted experimental $N O E$ was determined to $\eta=0.0054$ (corresponding to $r=2.9 \AA$ ), i.e., closer to the value predicted for the $S$-model $(\eta=0.0032, r=3.2 \AA)$, than that predicted for the $R$-model $(\eta=0.0144, r=2.5 \AA)$. 


\section{Confirmation of the $\mathrm{C} 14$ configuration by anisotropic NMR parameters}

Anisotropic NMR parameters have emerged as powerful tools in structural elucidation [35, 36]. Residual dipolar coupling (RDC) depend on the relative orientation of the ${ }^{13} \mathrm{C}-{ }^{1} \mathrm{H}$ bond vectors, while residual chemical shift anisotropy (RCSA) depend on the relative orientations of the carbon chemical shielding tensors. When combined, they can provide the configuration of stereogenic centers that are difficult to establish by traditional methods. A method described by Liu et al. [35] utilizing poly $(\gamma-$ benzyl-L-glutamate) (PBLG) to form a liquid crystal that induces anisotropy in chloroform- $d_{1}$ was employed in the present study. ${ }^{13} \mathrm{C}$ residual chemical shifts were referenced to TMS, and combined with RDC data from HSQC-IPAP spectra (Additional file 1: Figs. S14-S16, Tables S1 and S2). In the comparison of the experimental and theoretical anisotropic parameters for the commafric A the $S$-model provided lower quality factors $(Q=0.19)$ than the $R$-model $(Q=0.33$, Fig. 5$)$. Based on the anisotropic parameters, together with the VCD and NOE data, we conclude that commafric A's stereocenter C14 has the (S)-configuration.

Based on the above experimental evidence the structure of the novel compound commafric A was elucidated as $(3 S, 4 S, 14 S, 7 E, 17 E, 21 Z)$-3,30-dihydroxypodioda-7,17,21-trien-4-carboxylic acid.

In vitro anti-proliferative effect of the $\mathrm{MeOH}$ extract, $n$-hexane fraction, and isolated compounds

The anti-proliferative effects of the crude $\mathrm{MeOH}$ extract, $n$-hexane fraction, and isolated compounds commafric $\mathrm{A}$
Table $4 \mathrm{IC}_{50}$ values of $\mathrm{MeOH}$ extract, $n$-hexane fraction, and isolated compounds of resin of Commiphora africana against four cancer cell lines using SRB assay

\begin{tabular}{llccc}
\hline Sample & \multicolumn{4}{l}{ Cell lines and $\mathbf{I C}_{\mathbf{5 0}}(\boldsymbol{\mu} \mathbf{g} / \mathbf{m l})$} \\
\cline { 2 - 5 } & A549 & A2780 & MIA-PaCa-2 & SNU638 \\
\hline MeOH extract & 3.55 & 9.98 & 19.20 & 10.09 \\
$n$-Hexane fraction & 9.64 & 9.62 & 17.21 & 10.30 \\
a-Amyrin & 9.28 & 21.96 & 16.14 & 28.22 \\
Commafric A & 4.52 & 10.17 & 10.04 & 9.73 \\
Etoposide & 0.2 & 0.34 & 0.42 & 0.14 \\
\hline
\end{tabular}

$I C_{50}$ (Inhibition of cell growth by $50 \%$ ), data was generated by experiments performed in triplicates

and $\alpha$-amyrin were tested for four cancer cell lines, A549 (non-small cell lung cancer), A2780 (ovarian cancer), MIA-PaCa-2 (pancreatic cancer), and SNU638 (stomach cancer). The crude methanol extract showed a strong anti-proliferative activity against $\mathrm{A} 549\left(\mathrm{IC}_{50}=3.55 \mu \mathrm{g} /\right.$ $\mathrm{ml}$ ) (Table 4, Additional file 1: Fig. S17). The crude extract exhibited weaker activity against A2780, SNU-638, and MIA-Paca-2 compared with A549 cell lines. Among the cell lines tested the methanol crude extract showed strong effect on A549 cell lines $(3.55 \mu \mathrm{g} / \mathrm{ml})$. The $n$-hexane fraction exhibited significant inhibition of cell proliferation on the all four cell lines with dose dependent relationship in vitro. However, it was less sensitive and had a weaker net growth effect on A549 cell lines compared with the crude methanol extract (Table 4, Additional file 1: Fig. S17).
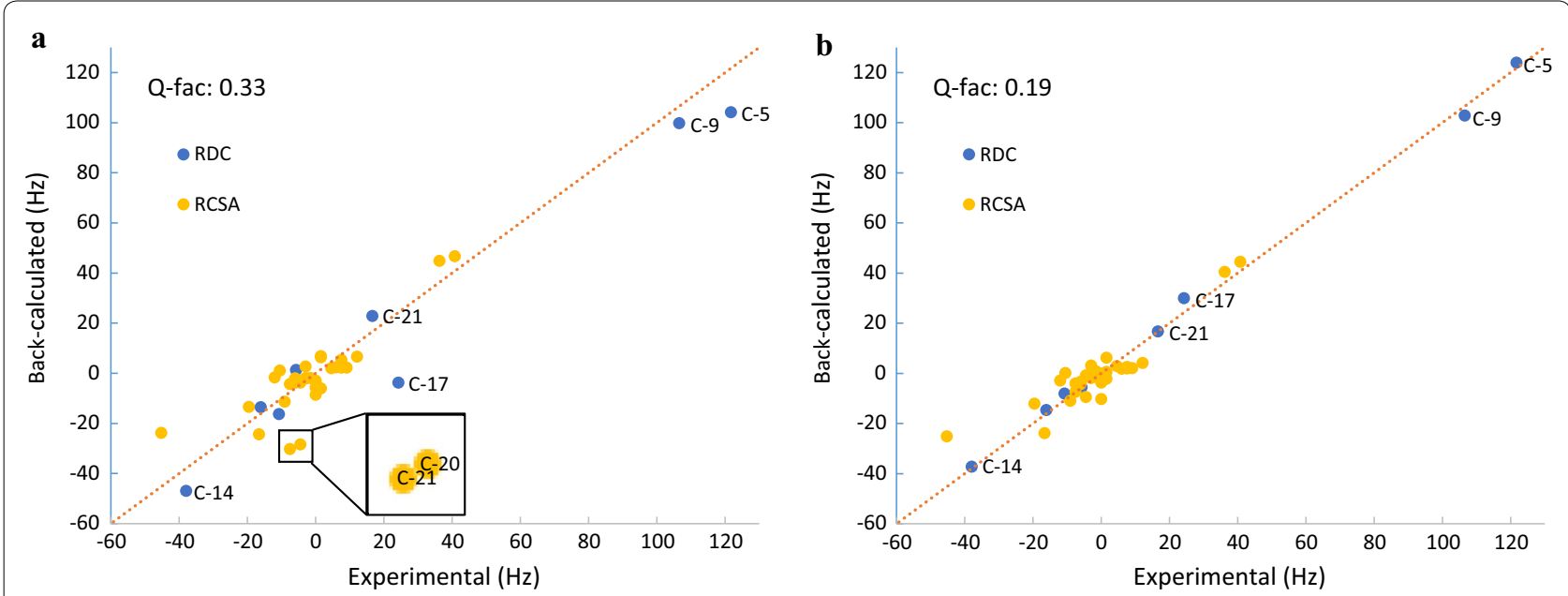

Fig. 5 Stereochemical differentiation between the $\mathbf{a} R$ - and $\mathbf{b} S$ configurations of C 14 in commafric $A$ using RDC and RCSA data collected in PBLG, showing the best agreement between experimental and theoretical data for the $S$ configuration 


\section{Discussion}

A number of bioactive compounds were previously reported from different Commiphora species. In this study, the $n$-hexane fraction of $C$. africana resin yielded a new compound commafric A. Cancer, cardiovascular diseases, chronic respiratory disorders and diabetes are the primary cause of deaths worldwide. The knowledge of herbal medications and anticancer activity tests assist in the development of important anticancer drugs [37].

In our study for in vitro anti-proliferative activity, we found that the crude extract and related $n$-hexane fraction is lower than $30 \mu \mathrm{g} / \mathrm{ml}$, which is within the limit of criteria set by the American National Cancer Institute for further purification [38]. For compound 1, a moderate anti-proliferative activity was observed for the A549 cancer cell lines, with $\mathrm{IC}_{50}$ value of $4.52 \mu \mathrm{g} / \mathrm{ml}$. This is comparable with the activity of the crude extract and more than twice better than for $\alpha$-amyrin. On the other hand, compound 1 showed weak anti-proliferative effects $>9 \mu \mathrm{g} / \mathrm{ml}$ for the other cell lines. The compound exhibited about twice higher activity on MIA-PaCa-2 compared with the methanol extract. The presence of carboxylic acid or terminal hydroxyl group in the compound might be the reason for its bioactivity. $\alpha$-Amyrin (2) having an ursane skeleton showed weaker activity on A549, A2780, and SNU638 cell lines compared with both compound $\mathbf{1}$ and the crude methanol extract. Compounds with similar skeleton to $\alpha$-amyrin such as ursolic acid and its derivatives showed strong anti-proliferative activity against ovarian carcinoma, pancreatic carcinoma, prostate cancer, cervical carcinoma, hepatic cancer, breast cancer, colorectal cancer, leukemia, neuroma, and colon adenocarcinoma [39]. The weak activity of $\alpha$-amyrin might be due to lack of carboxylic acid group. According to the literature on $\alpha$-amyrin pentacyclic triterpenes stimulate proliferation of human keratinocytes but do not protect them against UVB damage [40-42]. A review on antitumor effect of triterpene acid compounds revealed that triterpene acid type compounds have many effects including antiinflammatory, regulating blood sugar level, antiviral, and antitumor activity. More important, triterpene acid type compounds have become one of the most popular topics recently because of its selective toxic effects on cancer cells and harmless to normal cells [43].

The tricyclic triterpene acid $(3 S, 4 S, 14 S, 7 E, 17 E, 21 Z)$ 3,30-dihydroxypodioda-7,17,21-trien-4-carboxylic acid (commafric A) was isolated from the $n$-hexane fraction of the resin of $C$. africana and its structure was determined. It showed the variable $\mathrm{IC}_{50}$ values against the four cancer cell lines studied. The anti-proliferative effect against non-small cell lung cancer (A549) cells with $\mathrm{IC}_{50}$ values of $4.52 \mu \mathrm{g} / \mathrm{ml}$ was the highest among the cancer cells tested. The anti-proliferative effect suggests that commafric A has a potential in further investigations as a drug against different cancer lines. Further work is required to evaluate the mechanism of action of the commafric $\mathrm{A}$ as an antitumor agent against non-small cell lung cancer and evaluate its anti-proliferative on a number of cancer cell lines. Further isolation of compounds from the resin and other parts of this plant will be pursued which might yield some novel bioactive compounds.

\section{Supplementary information}

Supplementary information accompanies this paper at https://doi. org/10.1186/s13765-020-00499-w.

Additional file 1. Additional figures and tables

\section{Abbreviations}

HRESIMS: High resolution electrospray ionization mass spectroscopy; SRB: Sulphorhodamine B; VCD: Vibrational Circular Dichroism; RDC Residual dipolar coupling; RCSA: Residual chemical shift anisotropy; PBLG: Poly( $\gamma$-benzyl-L-glutamate).

\section{Acknowledgements}

We thank Prof. Ermias Dagne for initiating a research project work on the chemical composition of Commiphora resins especially those of Ethiopian origin in his research laboratory and his assistance in this study.

\section{Authors' contributions}

WD conducted the experimental studies such as extraction, isolation, characterization of compounds. WD also contributed in drafting the manuscript. PB and EB were involved in VCD analysis. JI and FG performed NMR analysis. JSMS participated in the interpretation of the NMR data and substantially revised the manuscript draft. AJAa supervised the project. SU and SL conducted the bioassay and HRMS analysis. YJ and ZS contributed the crucial help in supervision of the bioassay tests. AD conceptualized, designed and directed the study. All authors read and approved the final manuscript.

\section{Funding}

Financial support for this work such as research materials required for extraction, isolation of compounds and cytotoxicity tests was provided by National Research Foundation of Korea (No. 2016K1A3A1A09939937), RDA Troms: TFK2014-207, Norway provided support in materials required for NMR studies. Funding from Digital Life Norway/Research Council of Norway, project ID: 269425, is gratefully acknowledged. Adama Science and Technology University supported for some research materials required for extraction, isolation of compounds and salary of WD and AD. The Czech Grant Agency (18-05770S) provided salary for PB and EB, Ministry of Education (LTC17012 and CZ.02.1.0 1/0.0/0.0/16_019/0000729) provided computational resources. The funders of Grants play no role in the design of the study and collection, analysis, and interpretation of data and in writing the manuscript. All the responsibilities starting from the design of the study up to the write up of the manuscript were undertaken by the authors.

\section{Availability of data and materials}

The datasets used and analysed during the current study are available from the corresponding author on reasonable request.

\section{Ethics approval and consent to participate}

Not applicable because we did not work with animals or humans.

Consent to publish

Not applicable.

Competing interests

The authors declare that they have no competing interests. 


\begin{abstract}
Author details
1 Department of Applied Chemistry, Adama Science and Technology University, Adama, Ethiopia. ${ }^{2}$ Department of Chemistry, UiT the Arctic University of Troms $\varnothing, 9037$ Troms $\varnothing$, Norway. ${ }^{3}$ Institute of Organic Chemistry and Biochemistry, Academy of Sciences, Flemingovo Náměstí 2, Dejvice, 16610 Prague 6, Czech Republic. ${ }^{4}$ Department of Analytical Chemistry, University of Chemistry and Technology, Technická 5, 16628 Prague, Czech Republic. ${ }^{5}$ Bio \& Drug Discovery Division, Korea Research Institute of Chemical Technology, Daejeon, Republic of Korea. ${ }^{6}$ Institute of Pharmaceutical Science, Adama Science and Technology University, Adama, Ethiopia.
\end{abstract}

Received: 3 January 2020 Accepted: 28 February 2020

Published online: 17 March 2020

\section{References}

1. Aziz MM, Raza MA, Saleem H, Wajid M, Bashir K, Ikram M (2014) Medicinal values of herbs and plants, importance of phytochemical evaluation and ethnopharmacological screening: an illustrated review essay. J Pharm Cosmet Sci 2(1):6-10

2. Burkill HM (1994) The useful plants of west tropical Africa. Volume 2: Families El: Royal Botanic Gardens

3. Adebayo H, Aliyu R, Gatsing D, Garba H (2006) The effects of ethanolic leaf extract of Commiphora africana (Burseraceae) on lipid profile in rats. Int J Pharmacol 2(6):618-622

4. Akor J, Anjorin T (2009) Phytochemical and antimicrobial studies of Commiphora africana root extracts. Int J Agric Biol 11(6):795-797

5. Abbiw D (1990) Useful plants of Ghana, Intermediate Tech. Publication London, Royal Botanic Gardens, Kew, p 207

6. Worku A, Lemenih M, Fetene M, Teketay D (2011) Socio-economic importance of gum and resin resources in the dry woodlands of Borana, southern Ethiopia. Forests Trees Livelihoods. 20(2-3):137-155

7. Ahmed IM, Gadir SA, Elgilany EE, Abdallah TM (2016) Commiphora africana resin phytochemical analysis and some biological aspects. Europ J Med Plant 13(3):1-11

8. Mullauer FB, Kessler JH (2019) Medema JP (2009) Betulin is a potent antitumor agent that is enhanced by cholesterol. PLoS ONE 4(4):e1. https:// doi.org/10.1371/journal.pone.0005361

9. Aiken C, Chen $\mathrm{CH}$ (2005) Betulinic acid derivatives as HIV-1 antivirals. Trends Mol Med 11(1):31-36

10. Brieskorn $\mathrm{CH}$, Noble $\mathrm{P}$ (1983) Two furanoeudesmanes from the essential oil of myrrh. Phytochemistry 22(1):187-189

11. Dekebo A, Dagne E, Sterner O (2002) Furanosesquiterpenes from Commiphora sphaerocarpa and related adulterants of true myrrh. Fitoterapia 73(1):48-55

12. Dolara P, Luceri C, Ghelardini C, Monserrat C, Aiolli S, Luceri F, Lodovici M, Menichetti S, Romanelli MN (1996) Analgesic effects of myrrh. Nature 379(6560):29

13. Dekebo A, Dagne E, Hansen LK, Gautun OR, Aasen AJ (2000) Crystal structures of two furanosesquiterpenes from Commiphora sphaerocarpa. Tetrahedron Lett 41(50):9875-9878

14. Başer K, Demirci B, Dekebo A, Dagne E (2003) Essential oils of some Boswellia spp, myrrh and opopanax. Flavour Fragrance J 18(2):153-156

15. Messina F, Gigliarelli G, Palmier A, Marcotullio C (2017) Furanodienone: an emerging bioactive furanosesquiterpenoid. Curr Org Chem 21(4):305-310

16. Nguyen TT, Truong BN, Mai HDT, Litaudon M, Do Thi T, Chau VM, Pham VC (2017) Cytotoxic dammarane-type triterpenoids from the leaves of Viburnum sambucinum. Bioorganic Med Chem Lett 27(8):1665-1669

17. Dekebo A, Dagne E, Curry P, Gautun OR, Aasen AJ (2002) Dammarane triterpenes from the resins of Commiphora confusa. Bull Chem Soc Ethiopia 16(1):81-86

18. Yan H-J, Wang J-S, Kong L-Y (2014) Cytotoxic dammarane-type triterpenoids from the stem bark of Dysoxylum binecteriferum. J Nat Prod 77(2):234-242

19. Dekebo A, Lang M, Polborn K, Dagne E, Steglich W (2002) Four lignans from Commiphora erlangeriana. J Nat Prod 65(9):1252-1257

20. Habtemariam S (2003) Cytotoxic and cytostatic activity of erlangerins from Commiphora erlangeriana. Toxicon 41(6):723-727

21. Lodeiro S, Xiong Q, Wilson WK, Kolesnikova MD, Onak CS, Matsuda SP (2007) An oxidosqualene cyclase makes numerous products by diverse mechanisms: a challenge to prevailing concepts of triterpene biosynthesis. J Am Chem Soc 129(36):11213-11222

22. Arai Y, Hirohara M, Ageta H (1989) Fern constituents: three new skeletal triterpenoid hydrocarbons isolated from Polypodiodes niponica. Tetrahedron Lett 30(51):7209-7212

23. Frisch M, Trucks G, Schlegel H, Scuseria G, Robb M, Cheeseman J, Scalmani G, Barone V, Petersson G, Nakatsuji H (2016) Gaussian 16, Revision A. 03, Gaussian, Inc., Wallingford CT

24. Becke AD (1993) Density functional thermochemistry III The role of exact exchange. J Chem Phys 98(7):5648-5652

25. Cossi M, Rega N, Scalmani G, Barone V (2003) Energies, structures, and electronic properties of molecules in solution with the C-PCM solvation model. J Comput Chem 24(6):669-681

26. Stephens P (1987) Gauge dependence of vibrational magnetic dipole transition moments and rotational strengths. J Phys Chem 91(7):1712-1715

27. Stephens P, Ashvar C, Devlin F, Cheesemano J, Frischo M (1996) Ab initio calculation of atomic axial tensors and vibrational rotational strengths using density functional theory. Mol Phys 89(2):579-594

28. Skehan P, Storeng R, Scudiero D, Monks A, McMahon J, Vistica D, Warren JT, Bokesch H, Kenney S, Boyd MR (1990) New colorimetric cytotoxicity assay for anticancer-drug screening. J Nat Cancer Inst 82(13):1107-1112

29. Otuki MF, Ferreira J, Lima FV, Meyre-Silva C, An Malheiros, Muller LA, Cani GS, Santos AR, Yunes RA, Calixto JB (2005) Antinociceptive properties of mixture of a-amyrin and $\beta$-amyrin triterpenes: evidence for participation of protein kinase $C$ and protein kinase A pathways. J Pharmacol Exp Ther 313(1):310-318

30. Aragao GF, Carneiro LM, Júnior AP, Bandeira PN, Lemos TL, Viana GS (2007) Antiplatelet activity of a-and $\beta$-amyrin, Isomeric mixture from Protium heptaphyllum. Pharm Biol 45(5):343-349

31. Vázquez LH, Palazon J, Navarro-Ocaña A (2012) The pentacyclic triterpenes \& \#x03B1; $\beta$-amyrins: A review of sources and biological activities. In: Vázquez LH (ed) Phytochemicals - A global perspective of their role in nutrition and health. IntechOpen, New York, pp 487-502

32. Saurí J, Parella T, Espinosa JF (2013) CLIP-HSQMBC: easy measurement of small proton-carbon coupling constants in organic molecules. Organic Biomol Chem 11(27):4473-4478

33. Stuppner H, Moller E (1993) Cucurbitacins with unusual side chains from Picrorhiza kurroa. Phytochemistry 33(5):1139-1145

34. Tai T, Shingu T, Kikuchi T, Tezuka Y, Akahori A (1995) Triterpenes from the surface layer of Poria cocos. Phytochemistry 39(5):1165-1169

35. Liu Y, Cohen RD, Gustafson KR, Martin GE, Williamson RT (2018) Enhanced measurement of residual chemical shift anisotropy for small molecule structure elucidation. Chem Commun 54(34):4254-4257

36. Liu Y, Navarro-Vázquez A, Gil RR, Griesinger C, Martin GE, Williamson RT (2019) Application of anisotropic NMR parameters to the confirmation of molecular structure. Nat Protoc 14(1):217

37. Saleem H, Zengin G, Ahmad I, Lee JTB, Htar TT, Mahomoodally FM, Naidu $\mathrm{R}$, Ahemad N (2019) Multidirectional insights into the biochemical and toxicological properties of Bougainvillea glabra (Choisy.) aerial parts: a functional approach for bioactive compounds. J Pharmaceut Biomed 170:132-138

38. Radovanovic A (2015) Evaluation of potential cytotoxic effects of herbal extracts. Serbian J Exp Clin Res 16(4):333-342

39. Chudzik M, Korzonek-Szlacheta I, Król W (2015) Triterpenes as potentially cytotoxic compounds. Molecules 20(1):1610-1625

40. Chaturvedula VP, Schilling JK, Miller JS, Andriantsiferana R, Rasamison VE, Kingston DG (2004) New cytotoxic terpenoids from the wood of vepris $p$ unctata from the Madagascar Rainforest. J Nat prod 67(5):895-898

41. Biskup E, Gołębiowski M, Gniadecki R, Stepnowski P, Łojkowska E (2012) Triterpenoid a-amyrin stimulates proliferation of human keratinocytes but does not protect them against UVB damage. Acta Biochim Pol 59(2):255-260

42. Sun H, Fang W-S, Wang W-Z, Hu C (2006) Structure-activity relationships of oleanane-and ursane-type triterpenoids. Bot Stud 47(4):339-368

43. Zhang W, Men X, Lei P (2014) Review on anti-tumor effect of triterpene acid compounds. J Cancer Res Ther 10(5):14

\section{Publisher's Note}

Springer Nature remains neutral with regard to jurisdictional claims in published maps and institutional affiliations. 